\title{
Does larder-hoarding affect the condition of chicks in urban kestrels?
}

\author{
Łukasz REJT \\ Museum \& Institute of Zoology, Polish Academy of Sciences, Wilcza 64, PL-00679 Warsaw, Poland; \\ e-mail: luka@miiz.waw.pl
}

\begin{abstract}
Hoarding by urban kestrels and its subsequent exploitation significantly increases the frequency and regularity of feeding during the early stage of the nestling period. Twelve kestrels' nests situated in various part of the city were chosen to test whether hoarding could affect the chicks' condition. Four nests (with 22 nestlings) were provided with food - one dead mouse per chick per day (F group) and 8 (43 nestlings) were used as a control group (NF). Nestlings were weighed daily, and the length of their tarsus was also measured when the oldest chick in the nest was 11 days old. $50 \%$ of the NF nests experienced a decrease in the number of nestlings but no nestlings were lost in any of the F nests. However, no significant differences were found between the groups either in body mass or tarsus length. A possible reason was the behaviour of the adults which could be interpreted as the regulation of the frequency of prey delivery depending on its presence or absence in the nest.
\end{abstract}

Key words: Kestrel, Falco tinnunculus, food caching, chicks' growth.

\section{Introduction}

Among kestrels Falco tinnunculus (L., 1758) inhabiting the open landscape, hunting birds and incubating females often cache (hide) whole or partly eaten prey - in most cases on the ground (e.g., LEAVER, 1951; ClegG, 1971; PARKER, 1977; Village, 1998). One obvious function of caching is to store prey that has been caught more frequently than is needed to satisfy hunger. Due to caching, kestrels may continue to hunt during times of increased food availability as well as ensuring that food is available for an evening meal (most obviously in winter) (VILlage, 1990). Urban kestrels in C Europe hunt mainly in the outskirts of towns and thus voles comprise the bulk of their prey. Prey may be caught up to several kilometres from the nest (e.g., PIKULA et al., 1984; Romanowski, 1996; RiEgerT \& FuCHS, 2004). Sometimes it may be hard to deliver enough prey for the chicks, especially when long-distance flights are difficult to manage. Such a phenomenon was observed in the lesser kestrel Falco naumanni (Fleisch, 1818) in Spain, where the urban population had a higher ratio of chick deaths caused by starvation in comparison with rural sites (TELLA et al., 1996). Adequate food delivery is crucial during the nestling period to ensure the development of the young. REJT et al. (2000) found that the feeding frequency of urban kestrels during the first two weeks of the chicks' lives outnumbered prey deliveries. They stated that larder-hoarding (i.e. the concen- tration of food in one location) by urban kestrels and its subsequent exploitation could significantly increase the frequency and regularity of feeding during the early stage of the nestling period. They also speculated that it might become a strong factor influencing the chicks' survival.

Despite the seemingly obvious survival value of food storing, few studies exist that have attempted to experimentally test the influence of food storing on various components of fitness (KÄLLANDER \& SMITH, 1990; VALERA et al., 2001; HoI et al., 2004) while some of these studies' results were unclear (e.g., DEWEY \& KenneDY, 2001). The most recent study carried out on rural kestrels was undertaken by MASSEMIN et al. (2002) who found no significant effect of supplementary feeding on chicks body mass.

The aim of this study was to investigate whether extra food in kestrels' nests affects chicks' growth during the early nestling phase, at which time caches have been reported to be the largest due to lower demand (KÄLlANDER \& SMITH, 1990). This experiment should provide an answer to the question of whether urban kestrels' breeding biology could be significantly affected by hoarding behaviour.

\section{Material and methods}

The study was conducted during 2002 in Warsaw, Poland $\left(52^{\circ} 13^{\prime} \mathrm{N}, 21^{\circ} 02^{\prime} \mathrm{E}\right)$. Twelve kestrel nests situated in var- 
Table 1. Body mass $(m)$ and tarsus length $(t)$ (means \pm SD) of kestrel chicks.

\begin{tabular}{|c|c|c|c|c|c|c|}
\hline & \multicolumn{3}{|c|}{ All chicks } & \multicolumn{3}{|c|}{ Only 11-day old chicks } \\
\hline & $\mathrm{F}$ & NFnl & NFl & $\mathrm{F}$ & NFnl & $\mathrm{NFl}$ \\
\hline$m(\mathrm{~g})$ & $125 \pm 21.58$ & $118.3 \pm 32.95$ & $110.5 \pm 20.98$ & $137.2 \pm 12.8$ & $142.3 \pm 5.8$ & $131.0 \pm 7.81$ \\
\hline$t(\mathrm{~mm})$ & $38.8 \pm 3.0$ & $36.6 \pm 6.3$ & $37.7 \pm 3.23$ & $40.7 \pm 1.0$ & $40.8 \pm 1.6^{a}$ & $40.3 \pm 1.04$ \\
\hline$n$ & 22 & 18 & 8 & 12 & 8 & 3 \\
\hline
\end{tabular}

Key: F - nests supplemented with food; NFnl - control group without chicks loses; NFl - nests from control group where at least one chick died during the experiment; $n$ - number of chicks measured, ${ }^{a} n=7$.

ious parts of the city were used in the experiment. Four of the nests were supplemented with food $(\mathrm{F})$ and 8 were used as controls (NF). In the first group, there were on average (mean $\pm \mathrm{SD}) 5.5 \pm 1.3$ chicks per nest $(4,5,6$ and 7 ), in the second - an average of $5.4 \pm 1.1(2 \times 4,2 \times 5,3 \times$ 6 and 7). Differences in the average chicks' number were not significant (Mann-Whitney $U$-test, $Z=0.17, P=0.86$ ). The nests were chosen randomly, but both the fed and unfed groups were located in comparable urbanised environments and were also close to each other.

All nests from the F group and most from the NF group were visited every day between 8:00 a.m. and 12:00 p.m. This is the main reason for the lower number of nestlings included in the statistical analysis. Chicks were weighed daily to the nearest $1 \mathrm{~g}$ starting from the day after the first one hatching. When the oldest chick in a nest was 11 days old, the tarsus length of each nestling was measured to the nearest $0.1 \mathrm{~mm}$. Dead dark-coloured mice - one per chick per day - were provided to the $\mathrm{F}$ nests. The average weight of the mouse (mean $\pm \mathrm{SD}$ ) was $22.3 \pm 6.2 \mathrm{~g}$. This corresponds to approximately half of the daily food requirement of kestrel nestlings (MASMAN et al., 1989). Food provisioning started the day after the first chick hatched. Both intact and partly eaten mice from previous feedings were removed every day, as were the remains of prey from NF nests. Two $\mathrm{F}$ nests were continuously monitored by video cameras to follow the fate of the supplemental food.

The experiment was terminated on the $11^{\text {th }}$ day after the first chick's hatching to avoid inducing premature departure from the nest. Statistics were carried out using STATISTICA 4.0. software.

\section{Results}

In four nests from the NF group, the number of chicks changed during the experiment due to nestling mortality. Thus, the average number of chicks in the NF group decreased to $4.9 \pm 1.5(n=8)$. However, differences in the number of chicks between the $\mathrm{F}$ and $\mathrm{NF}$ were still non-significant (Mann-Whitney $U$-test, $Z=0.69, P=$ $0.5)$.

Differences in the mean body mass of chicks $( \pm$ $\mathrm{SD})$ from $\mathrm{F}(125.0 \pm 21.6 \mathrm{~g})$ and $\mathrm{NF}$ groups (115.0 $\pm 29.6 \mathrm{~g}$; all nests - with and without chicks' losses) at day 11 were non-significant (Mann-Whitney $U$-test, $\left.Z=0.85, n_{1}=22, n_{2}=26, P=0.4\right)$. The measurement of daily differences in mean body mass showed that chicks from group $\mathrm{F}$ were always slightly heavier, but these differences were also not significant (Fig. 1). Comparisons were also made between nests where chick

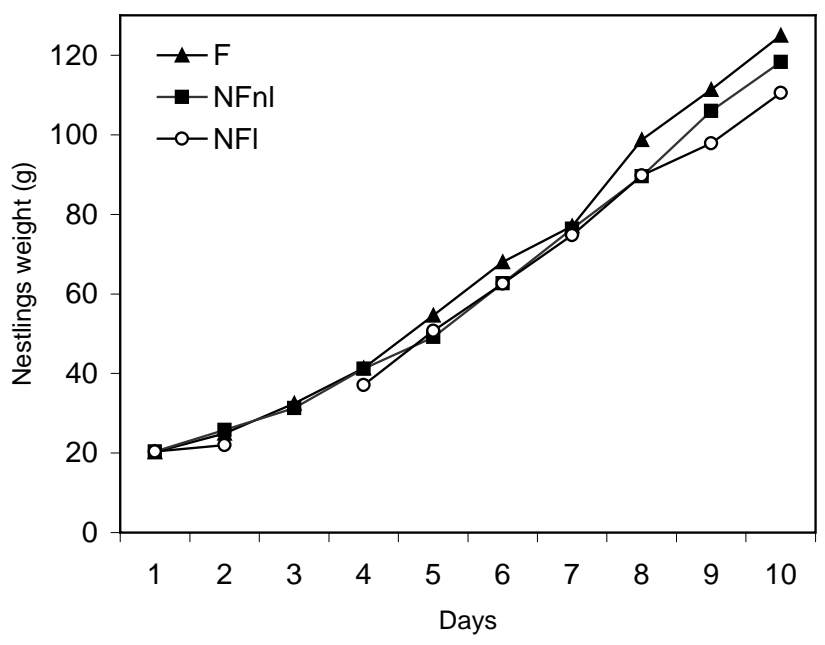

Fig. 1. Daily changes in nestlings' weight during experiment. F - nests supplemented with food, NFnl - control group without chicks loses, $\mathrm{NFl}$ - control group where at least one chick died during the experiment.

losses occurred with those where the number of chicks was unchanged (Tab. 1$): \mathrm{F}(n=4$ nests, there were no $\mathrm{F}$ nests with chick losses), NF without losses (NFnl, $n$ $=4)$, NF with chick losses (NFl, $n=4)$. These showed that body mass on the $11^{\text {th }}$ day of the chicks' lives was not significantly different (Kruskal-Wallis ANOVA, $\left.H_{(2, n=48)}=2.65, P=0.26\right)$. Differences in the mean body mass of $\mathrm{F}$ and NFnl chicks at day 11 were not significant (Mann-Whitney $U$-test, $Z=0.08, n_{1}=$ $22, n_{2}=18, P=0.93$, Tab. 1). Differences between $\mathrm{F}$ and NFl were also non-significant, but suggested a tendency toward being lighter in the NFl (MannWhithey $U$-test, $Z=1.74, n_{1}=22, n_{2}=8, P=0.082$, Tab. 1).

Slight but non-significant differences between $\mathrm{F}$ and NFnl were also found in tarsus length (MannWhitney $U$-test, $Z=0.72, n_{1}=22, n_{2}=18, P=0.47$, Tab. 1).

Among the oldest, i.e. 11-day-old chicks, those from NFnl nests were slightly heavier in comparison to the $\mathrm{F}$ group, but the difference was not significant (Mann-Whitney $U$-test, $Z=1.47, n_{1}=12, n_{2}=8, P$ $=0.14$, Tab. 1). When comparing NFl and NFnl, the mean body mass of the oldest chicks was slightly lower (Mann-Whitney $U$-test, $Z=2.04, n_{1}=8, n_{2}=3, P$ $=0.04$, Tab. 1). The tarsus length in $\mathrm{F}$ and $\mathrm{NF}$ was 
Table 2. Changes in chicks body mass $m$ (means $\pm \mathrm{SD}$ ) in relation to brood size.

\begin{tabular}{lccccc}
\hline & \multicolumn{2}{c}{$\mathrm{F}$} & $\mathrm{NF}$ & \multicolumn{2}{c}{$\mathrm{s}^{a}$} \\
\cline { 2 - 6 } & $\mathrm{b}$ & $\mathrm{s}$ & $\mathrm{b}$ & $\mathrm{b}^{a}$ & $110.3 \pm 22.68$ \\
\hline$m(\mathrm{~g})$ & $125.0 \pm 23.03$ & $125.0 \pm 15.98$ & $118.3 \pm 32.95$ & $110.6 \pm 22.65$ & 3 \\
$n$ & 18 & 4 & 18 & 5 & 3 \\
\hline
\end{tabular}

Key: $\mathrm{F}$ - nests supplemented with food; NF - control group; $\mathrm{b}$ - nests with 5 or more nestlings; $\mathrm{s}-$ nests with less than 5 nestlings; $n$ - number of nestlings measured; $\mathrm{s}^{a}$ - nests where at least one chick died during the study.

similar (Mann-Whitney $U$-test, $Z=0.098, n_{1}=12, n_{2}$ $=10, P=0.92)$.

All nests in the study were also divided into four groups by brood size: fed with $\geq 5$ chicks (Fb, $n=$ 3 nests), fed with $<5$ chicks (Fs, $n=1$ ), not fed with $\geq 5$ chicks (NFb, $n=4$ ) and not fed with $<5$ chicks (NFs, $n=1$ ). The body mass of chicks from all groups at day 11 was compared (Tab. 2). There were no differences between the two F-groups. The mean body mass in $\mathrm{NFb}$ was higher than in NFs. However, differences between all the groups were non-significant (Kruskal-Wallis ANOVA, $H_{(3, n=48)}=0.55, P=0.76$ ). Similar results were obtained if only nests with an unchanged number of nestlings were compared (KruskalWallis ANOVA, $\left.H_{(3, n=48)}=0.007, P=0.99\right)$.

\section{Discussion}

Indirect and some correlative evidence strongly suggests that hoarding food is important for the reproductive success of several species (KÄLLANDER \& SMITH, 1990). It is known that caching increased feeding frequency during the early stage of the nestling period in raptors (HolthuiJzen, 1990; REJT et al., 2000). Studies of mammals have shown that supplemental food (which could be defined as a special case of food caching) resulted in higher individual growth rates and increased survival of juveniles, among others (e.g., Desy \& Thompson, 1983).

In the present experiment, chicks supplemented with food and those not fed differed slightly in body mass, but the differences were not statistically significant (Tabs 1,2). Therefore, one cannot state without a doubt that extra food resulted in increased body weight and size of kestrel nestlings. However small differences observed on the $11^{\text {th }}$ day of life of the nestlings may indicate a trend in this direction. This is also supported by the interim results. Over the 11 days, body mass of the chicks from the $\mathrm{F}$ group was greater than those from the NF group. The opposite situation was not observed (Fig. 1). The body mass of $\mathrm{F}$ nestlings was somewhat greater than NF only when analysing the nestlings' total weight taken together (an average of $125 \mathrm{~g}$ vs. 118.3 $\mathrm{g}$ for nests with an unchanged number of nestlings). The opposite situation was observed when only the weight of the oldest, 11-day old nestlings was compared (in nests with no losses in nestling number) (an average of $137.2 \mathrm{~g}$ vs. $142.3 \mathrm{~g}$ ). This data may suggest that younger nestlings were able to compete more effectively for food with their older siblings in F nests - they grew faster and had greater body mass than younger nestlings from the NF group. This trend is also supported by the results of measurements of the tarsus (Tab. 1). No difference was seen in tarsus length between 11-day old chicks from groups $\mathrm{F}$ and $\mathrm{NF}$ (on average $40.7 \mathrm{~mm}$ vs. 40.3 $40.8 \mathrm{~mm}$ ). However, measurements taken from all chicks in the nest show those from group $\mathrm{F}$ with slightly longer tarsi (on average $38.8 \mathrm{~mm}$ vs. $37.6-36.6 \mathrm{~mm}$ ). Hatching asynchrony in altricial birds leads to a size hierarchy of nestlings within a brood resulting in a competitive disadvantage for the youngest chicks compared to older siblings, which in turn can lead to slower growth and higher mortality in the former (e.g., RICKLEFs, 1982). Theoretically then, having food stores (imitated in this experiment by the provision of extra food) could result in more even growth among all the nestlings in a clutch, resulting in greater body mass and size of the younger nestlings and, above all, a reduction in nestling loss. No nestlings were lost in any of the F nests, but $50 \%$ of the NF nests experienced a decrease in the number of nestlings during the 10-day duration of the experiment (average loss of 1 nestling, from 5.4 nestlings/nest to 4.9).

It was expected that the frequency of feedings of group F would be greater than that of group NF) and this would result in a greater and more regular provision of food to nestlings in group $\mathrm{F}$ (REJT et al., 2000). Due to the ongoing monitoring of two of the $\mathrm{F}$ nests, certain behaviours of the adults were observed which could be interpreted as the regulation of the frequency of prey delivery depending on its presence or absence in the nest. The female (and sometimes the male) removed some or all of the mice from the nest right after they had been placed there by the researcher. In subsequent hours, the male, and also the female, brought them back to the nest. Simply stated, when additional prey was present in the nest, the female did not harass the male to hunt (see also Estes \& MANnAN, 2003). The male, left alone by the female, did not hunt (or he was hunting, but the female did not take the prey from him to feed to the young). For a certain period of time, the mice provided during the experiment were the main source of food for group F young and they were fed prey caught by the adults themselves only after the store was exhausted. This is why the average frequency of feeding before providing the mice $(0.73 \pm 0.12$ feedings $/ \mathrm{h})$ 
and after providing the mice $(0.87 \pm 0.14 / \mathrm{h})$ did not differ significantly (Mann-Whitney $U$-test, $Z=1.5, n_{1}$ $\left.=7, n_{2}=6, P=0.13\right)$. A similar phenomenon was observed by MEIJER et al. (1988) during a pre-laying supplemental feeding experiment.

In studies done to date on birds, the availability of additional food affects several aspects of breeding biology (DiJKstra et al., 1982; MEIJER et al., 1988; Boutin, 1990; Meijer \& HALl, 1990; Wiebe \& BorTOlotti, 1995; Gehlbach \& RoberTs, 1997). It has been found, however, that the effects of extra food could be minimised or even cancelled out by parents' age, breeding density, food supply or weather (GEHLBACH \& RoBERTs, 1997). The possible influence of these factors was not considered in this study. Nestlings' survival (i.e., level of losses) could be affected by breeding density, the urbanisation gradient, availability of natural food or its composition (e.g., energy content of different prey categories: mammals, birds or reptiles). Also, the parents' age could impact on the survival of chicks in particular nests. Because both the $\mathrm{F}$ and NF groups were in the same urbanisation gradient, the eventual influence of breeding density or food availability on the results of the experiment can be ruled out. Therefore, the presence or absence of additional food imitating caching was the exclusive cause of slight differences in body mass and tarsus length. The study lasted only one season, so it was not possible to assess longer term differences in store exploitation between years of different prey availability. Despite this it can be assumed that the presence of supplemental food could affect the survival rate of nestlings, the competitive success of the youngest chicks and the level of hunting activity of the parent birds.

The results obtained in this study suggest that unlike other species of raptors inhabiting the urban environment (e.g., TELLA et al., 1996), kestrels can prevent their chicks from starvation during the early stage of the nestling period. It means that conservation projects undertaken to keep these birds inside cities (by erecting nest boxes, for instance), far from hunting places do not affect negatively urban populations of this species.

\section{Acknowledgements}

Study was financially supported by Committee for Scientific Researches (KBN), grant No. 6P04F03421.

\section{References}

Boutin, S. 1990. Food supplementation experiments with terrestrial vertebrates: patterns, problems, and the future. Can. J. Zool. 68: 203-220.

ClegG, T.M. 1971. Kestrel hiding prey. Scott. Birds 6: 276-277.
Desy, E.A. \& Thompson C.F. 1983. Effects of supplemental food on a Microtus pennsylvanicus population in Central Illinois. J. Anim. Ecol. 52: 127-140.

Dewey, S.R. \& Kennedy P.L. 2001. Effects of supplemental food on parental-care strategies and juvenile survival of Northern Goshawks. Auk 118: 352-365.

Dijkstra, C., Vursteen, L., DaAn, C. \& Masman, D. 1982. Clutch size and laying date in the kestrel Falco tinnunculus: effect of supplementary food. Ibis 24: 210-213.

Estes, W.A. \& MANnAN, R.W. 2003. Feeding behavior of Cooper's Hawks at urban and rural nests in southeastern Arizona. Condor 105: 107-116.

Gehlbach, F.R. \& Roberts, J.C. 1997. Experimental feeding of suburban Eastern Screech-Owl Otus asio has fewer effects on reproduction apart from non-experimental factors. J. Avian Biol. 28: 38-46.

Hoi, H., Kristin, A., Valera, F. \& Hoi, C. 2004. Clutch enlargement in Lesser Gray Shrikes (Lanius minor) in Slovakia when food is superabundant: A maladaptative response? Auk 121: $557-564$.

HolthuiJzen, A.M.A. 1990. Prey delivery, caching, and retrieval rates in nesting Prairie Falcons. Condor 92: 475-484.

Källander, H. \& Smith, H.G. 1990. Food storing in birds. An evolutionary perspective. Current Ornithol. 7: 147-207.

Leaver, D. 1951. Autumn behaviour of Kestrels. Brit. Birds 44: $27-28$.

Masman, D., Dijkstra, C., DaAn, S. \& Bult, A. 1989. Energetic limitation of avian parental effort: field experiments in the kestrel (Falco tinnunculus). J. Evol. Biol. 2: 435-455.

Massemin, S., Korpimäki, E., PÖyri, V. \& Zorn, T. 2002. Influence of hatching order on growth rate and resting metabolism of kestrels nestlings. J. Avian Biol. 33: 235-244.

Meijer, T., DaAn, S. \& Dijkstra, C. 1988. Female condition and reproduction: effects of food manipulation in free-living and captive Kestrels. Ardea 76: 141-154.

Meijer, T. \& HALl, M. 1990. Family planning in the Kestrel (Falco tinnunculus): the proximate control of covariation of laying date and clutch size. Behaviour 114: 117-136.

PArker, A. 1977. Kestrels hiding food. Brit. Birds 70: 339-340.

Pikula, J., Beklova, M. \& KubiK, V. 1984. The nidobiology of Falco tinnunculus. Acta Sci. Nat. Brno 18: 1-55.

Rejt, Ł., Turlejski, K., Bronche, K. \& Topczewski, A.M. 2000. Can food caching increase frequency of feedings in urban kestrels Falco tinnunculus? Acta Ornithol. 35: 217-221.

RiCKLEFS, R.E. 1982. Some consideration on sibling competition and avian growth rates. Auk 99: 141-147.

Riegert, J. \& Fuchs, R. 2004. Insects in the diet of urban kestrels from central Europe: an alternative prey or constant component of the diet? Ornis Fenn. 81: 23-32.

Romanowski, J. 1996. On the diet of urban kestrels (Falco tinnunculus) in Warsaw. Buteo 8: 123-130.

Tella, J.L., Hiraldo, F., Donazar-Sancho, J.A. \& Negro, J.J. 1996. Costs and benefits of urban nesting in the Lesser Kestrel, pp. 53-60. In: BirD, D.M., VARland, D.E. \& NEGRO, J.J. (eds) Raptors in urban landscapes, Academic Press, London.

Valera, F., Kristin, A. \& Hoi, H. 2001. Why does the Lesser Grey Shrike (Lanius minor) seldom store food? Determinants of impaling in an uncommon storing species. Behaviour 138: $1421-1436$

Village, A. 1990. The Kestrel. T \& A D Poyser, 430 pp.

Village, A. 1998. The Kestrel Falco tinnunculus. BWP Update 2: $121-136$.

Wiebe, K.L. \& Bortolotti, G.R. 1995. Egg size and clutch size in the reproductive investment of American kestrels. J. Zool., Lond. 237: 285-301.

Received October 26, 2004 Accepted May 26, 2005 